\title{
Locally invasive hepatic angiosarcoma: an unusual cause of massive haemothorax
}

\author{
YT WANG, SC WONG, A THOMAS \\ From the Departments of Medicine and General Surgery, Tan Tock Seng Hospital, and the Department of \\ Pathology, Singapore General Hospital, Singapore
}

We report a case of hepatic angiosarcoma in which the clinical course was dominated by haemothorax.

\section{Case report}

A 61-year-old male Chinese manual labourer was first seen in November 1980 because of a cough and haemoptysis. He had smoked 10 cigarettes a day for 30 years and consumed alcohol regularly for 10 years. Apart from bilateral rhonchi in the lungs, no abnormalities were found on clinical examination. A chest radiograph showed bilateral mid-zone and upper-zone opacities. Sputum smears showed acid-fast bacilli, and laryngeal swabs grew Mycobacterium tuberculosis. After regular treatment with primary antituberculosis drugs there was radiological improvement and bacteriological conversion.

Seventeen months later he was admitted to hospital because of right hypochondrial pain. Initially he was afebrile. His blood pressure was $130 / 90 \mathrm{~mm} \mathrm{Hg}$ and pulse 80 / min. Spider naevi, palmar erythema, peripheral lymphadenopathy, and digital clubbing were absent. The liver was palpable $3 \mathrm{~cm}$ beneath the costal margin. No hepatic rub or bruit was detected. A massive right pleural effusion was present (fig 1a). The haemoglobin concentration was $11.4 \mathrm{~g} / \mathrm{dl}$, the total white count $9.6 \times 10^{9} / 1$, and the platelet count $175 \times 10^{9} / 1$. Blood urea and serum electrolyte concentrations were normal. The serum albumin concentration was $29 \mathrm{~g} / \mathrm{l}$, serum globulin $39 \mathrm{~g} / \mathrm{l}$, serum bilirubin $1 \cdot 2$ $\mathrm{mg} / 100 \mathrm{ml}(20.4 \mu \mathrm{mol} / \mathrm{l})$, serum alkaline phosphatase 129 $\mathrm{U} / \mathrm{l}$, and serum glutamate-pyruvate transaminase $21 \mathrm{U} / \mathrm{l}$. His serum was positive for hepatitis B surface antigen by the reverse passive haemagglutination technique (RPHA). The $\alpha$-fetoprotein test was negative by counterimmune electrophoresis. Prothrombin and partial thromboplastin times were normal. An abdominal radiograph was normal. A radionuclide liver scan showed a filling defect in the superior aspect of the right lobe and features of cirrhosis. Right pleurocentesis yielded $700 \mathrm{ml}$ of frankly bloody fluid.

As bleeding into the right hemithorax continued pleurocentesis had to be repeated and eventually an intercostal tube was inserted. The patient was transfused with

Address for reprint requests: Dr Wang Yee Tang, Department of Medicine III, Tan Tock Seng Hospital, Moulmein Road, Singapore 1130.

Accepted 19 November 1982 several units of blood. Hepatic angiography showed a liver tumour in the right lobe invading the thorax (fig 1b). Therapeutic embolisation was attempted but failed, and exploratory surgery was therefore carried out via a thoracoabdominal approach. This showed a large hepatic tumour, which had eroded the diaphragm and invaded the right hemithorax. Parts of necrotic tumour slough were deposited in the adjacent pleural space but the rest of the pleura was free of tumour. Blood clots were evacuated from the pleural cavity and the hepatic artery was ligated. The patient continued to bleed into the right pleural space and died on the first postoperative day. The microscopic appearance of the tumour is shown in fig 2 .

\section{Discussion}

Hepatic angiosarcoma is a very rare tumour, ' which has been linked epidemiologically with thorotrast, vinyl chloride, arsenic, and androgenic anabolic steroids. ${ }^{2}$ Our patient was not known to have been exposed to any of these. Occult arsenic poisoning, however, may result from ingestion of some Chinese herbal mixtures. The presence of hepatitis B surface antigen in the patient's serum may be purely fortuitous as the incidence of the antigen in the serum of symptomless blood donors among Singaporean Chinese is $13 \%$ by RPHA. ${ }^{3}$ Although he presented with abdominal pain, the most important clinical feature was massive haemothorax. Patients with hepatic angiosarcoma are known to have serious haemorrhagic complications. ${ }^{14}$ Of 103 patients reviewed by Locker et al, 28 had clinically apparent intra-abdominal bleeding (excluding gastrointestinal bleeding) and five disseminated intravascular coagulopathy. ${ }^{1}$ In none of the patients reviewed was haemothorax reported. Our patient had neither intraabdominal bleeding nor any evidence of disseminated intravascular coagulopathy. The tumour had invaded through the diaphragm and bled into the right pleural space.

Thus hepatic angiosarcoma with transdiaphragmatic invasion and massive bleeding into the right hemithorax, though rare, should be considered in the differential diagnosis of right haemothorax.

\section{References}

' Locker GY, Doroshow JH, Zwelling LA, Chabner BA. The clinical features of hepatic angiosarcoma: a report of four cases and a review of the English literature. Medicine (Baltimore) 1979;58:48-64. 

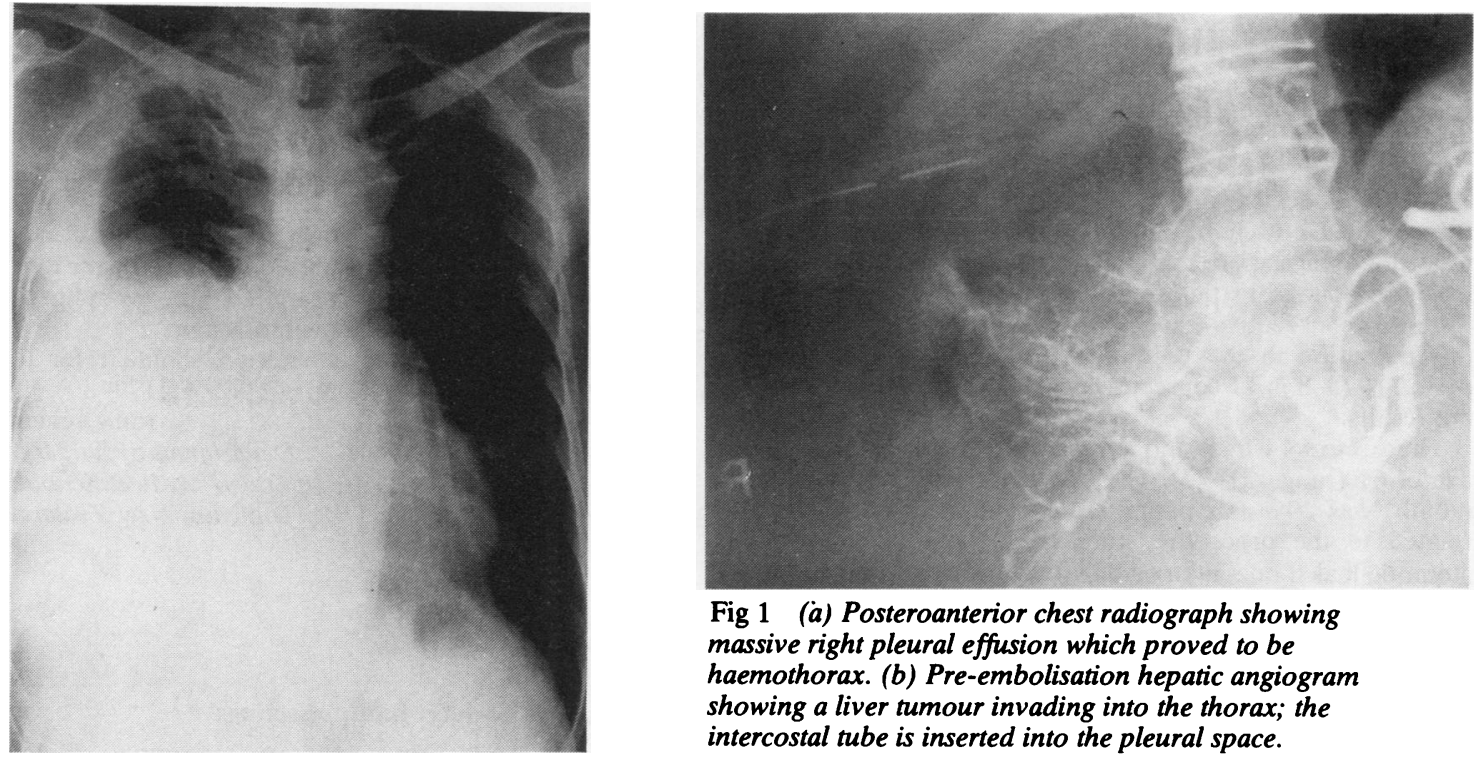

Fig 1 (a) Posteroanterior chest radiograph showing massive right pleural effusion which proved to be haemothorax. (b) Pre-embolisation hepatic angiogram showing a liver tumour invading into the thorax; the intercostal tube is inserted into the pleural space.

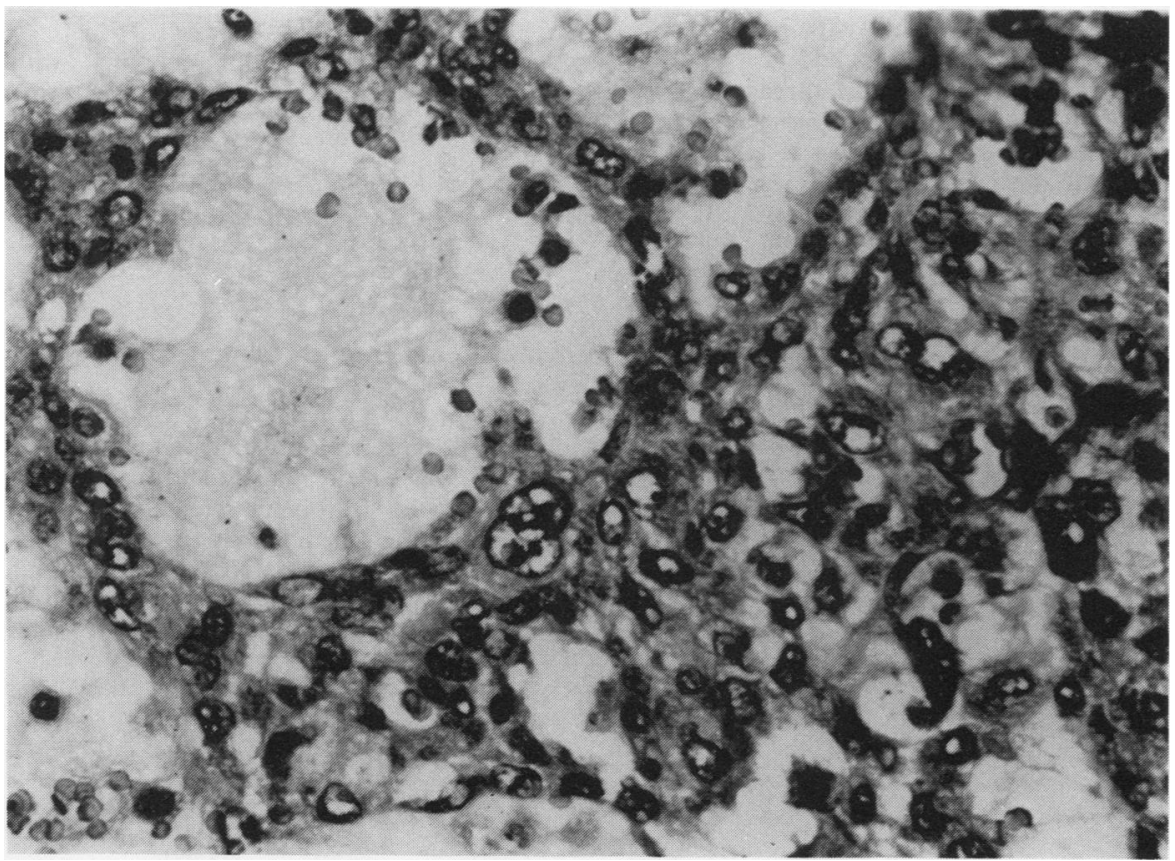

Fig 2 Microscopic appearance of the tumour with malignant endothelial cells lining irregular vascular channels. (Haematoxylin and eosin, $\times$ 400.)

${ }^{2}$ Falk H, Thomas LB, Popper H, Ishak KG. Hepatic angiosarcoma associated with androgenic-anabolic steroids. Lancet 1979;ii:1120-3.

${ }^{3}$ Chan SH. Chronic hepatitis in Singapore. Annuals of the
Academy of Medicine, Singapore 1980;9:179-81.

4 Truell JE, Peck SD, Reiquam CW. Haemangiosarcoma of the liver complicated by disseminated intravascular coagulation Gastroenterology 1973;65:936-42. 